\title{
Long-term outcomes of diabetic patients with critical limb ischemia treated by autologous cell therapy compared to conservative therapy
}

Nemcova A., Jirkovska A., Bem R., Fejfarova V., Woskova V., Pysna A., Dubsky M.

Institute for Clinical and Experimental Medicine, Prague, Czech Republic

\section{BACKGROUND}

- Autologous cell therapy (ACT) is a new therapeutic approach for patients with critical limb ischemia (CLI) who are not eligible for standard revascularization (no-option CLI)

- Data about long-term clinical outcomes of ACT in these patients are lacking

\section{AIM}

The aim of our study was to compare the mortality and amputation rates of patients with diabetic foot (DF) and CLI treated by ACT with patients treated conservatively

Table 1. Basic characteristics of patients

\begin{tabular}{|c|c|c|c|}
\hline & $\begin{array}{c}\text { ACT group } \\
n=45\end{array}$ & $\begin{array}{l}\text { Control group } \\
\qquad n=42\end{array}$ & $\mathbf{p}$ \\
\hline Age (years) & $64.4 \pm 14$ & $67.5 \pm 9$ & NS \\
\hline Gender (\% of men) & 80 & 71.4 & NS \\
\hline Type of diabetes (\% DM2T) & 82.2 & 90.5 & NS \\
\hline Diabetes duration (years) & $24.2 \pm 14$ & $20.9 \pm 10.8$ & NS \\
\hline Glycated hemoglobin $(\mathrm{mmol} / \mathrm{mol})$ & $59.6 \pm 14$ & $62 \pm 15.2$ & NS \\
\hline Ischemic heart disease (\%) & 64.4 & 45.2 & 0.07 \\
\hline Hypertension (\%) & 91.1 & 92.9 & NS \\
\hline Renal failure - dialysis (\%) & 20 & 11.9 & NS \\
\hline Immunosuppressive therapy (\%) & 17.8 & 7.1 & NS \\
\hline Angiographic finding - Graziani (mean $\pm S D$ ) & $5.0 \pm 0.9$ & $5.1 \pm 0.8$ & NS \\
\hline Baseline $\mathrm{TcPO}_{2}$ values $(\mathrm{mmHg})$ & $17.7 \pm 10.4$ & $16.5 \pm 9.8$ & NS \\
\hline
\end{tabular}

Figure 1. The rate of major amputation in patients treated by ACT compared to conservative therapy over 3 years

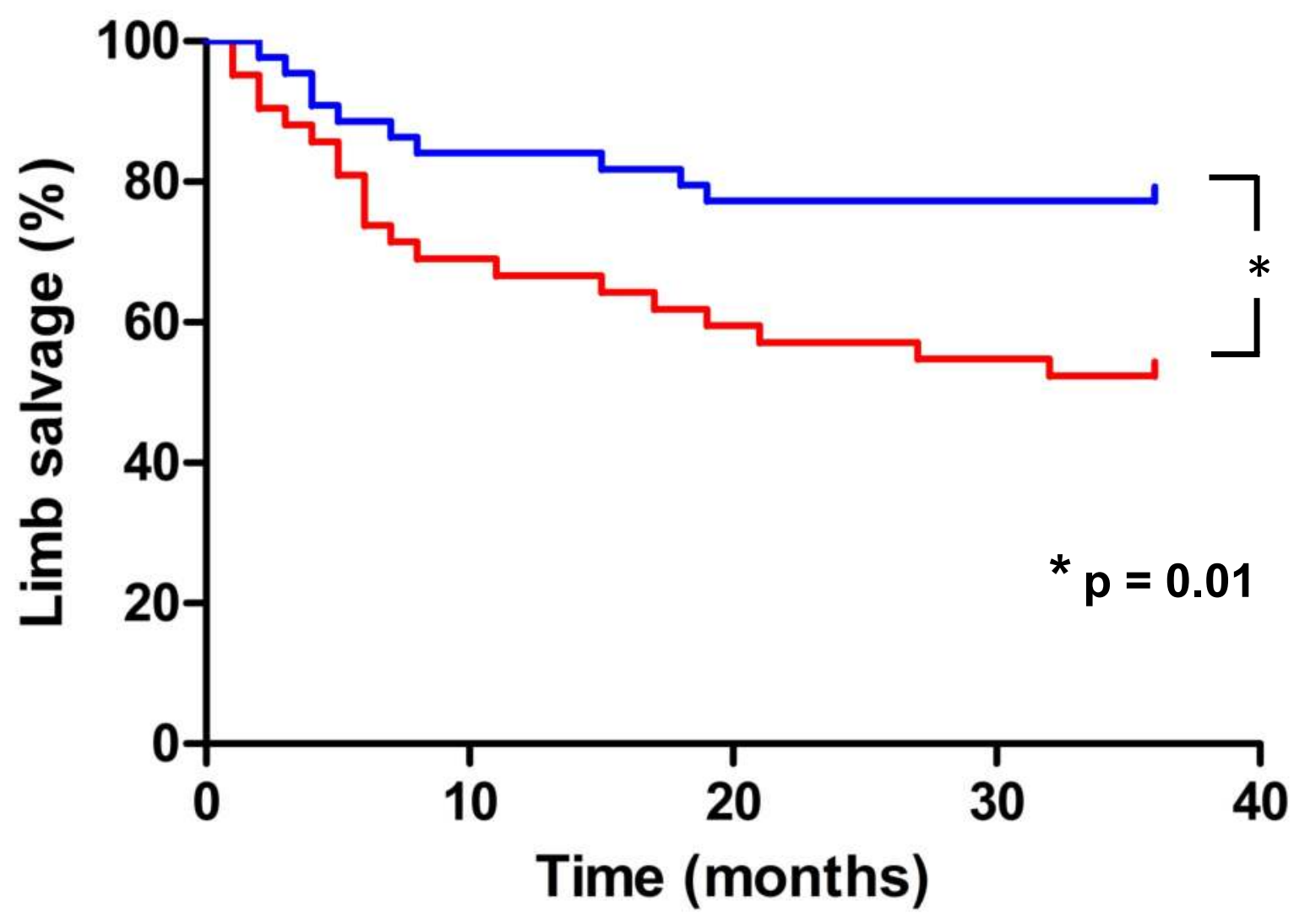

$\perp \mathrm{ACT} \perp$ Conservative therapy

\section{METHOD}

- Eighty-seven patients with DF and no-option CLI treated in our foot clinic over 5 years were enrolled into the study (Table 1.)

- No-option CLI was defined as $\mathrm{TcPO}_{2}{ }^{*}<30 \mathrm{mmHg}$ with ulcers after unsuccessful standard revascularization

- Forty-five patients were treated by ACT

- Forty-two patients were treated conservatively and formed the control group

- Mortality and rate of major amputation were assessed over 3 years follow-up period

${ }^{*} \mathrm{TcPO}_{2}$ - transcutaneous oxygen pressure

\section{RESULTS}

- The rate of major amputation after 3 years was significantly lower in ACT group in comparison with control group (22.2\% vs. $47.6 \%, p=0.01)$, Figure 1 .

- There was a trend to lower mortality $(24.4 \%$ vs. $42.9 \%, p$ $=0.07$ ) and slightly higher frequency of ischemic heart disease $(64.4 \%$ vs. $45.2 \%, p=0.07)$ in ACT group in comparison with control group, Figure 2 .

- Causes of major amputation after ACT: progression of infection $(70 \%)$, progression of ischemia $(20 \%)$, pain or others $(10 \%)$

Figure 2. Mortality rate in patients treated by ACT compared to conservative therapy over 3 years

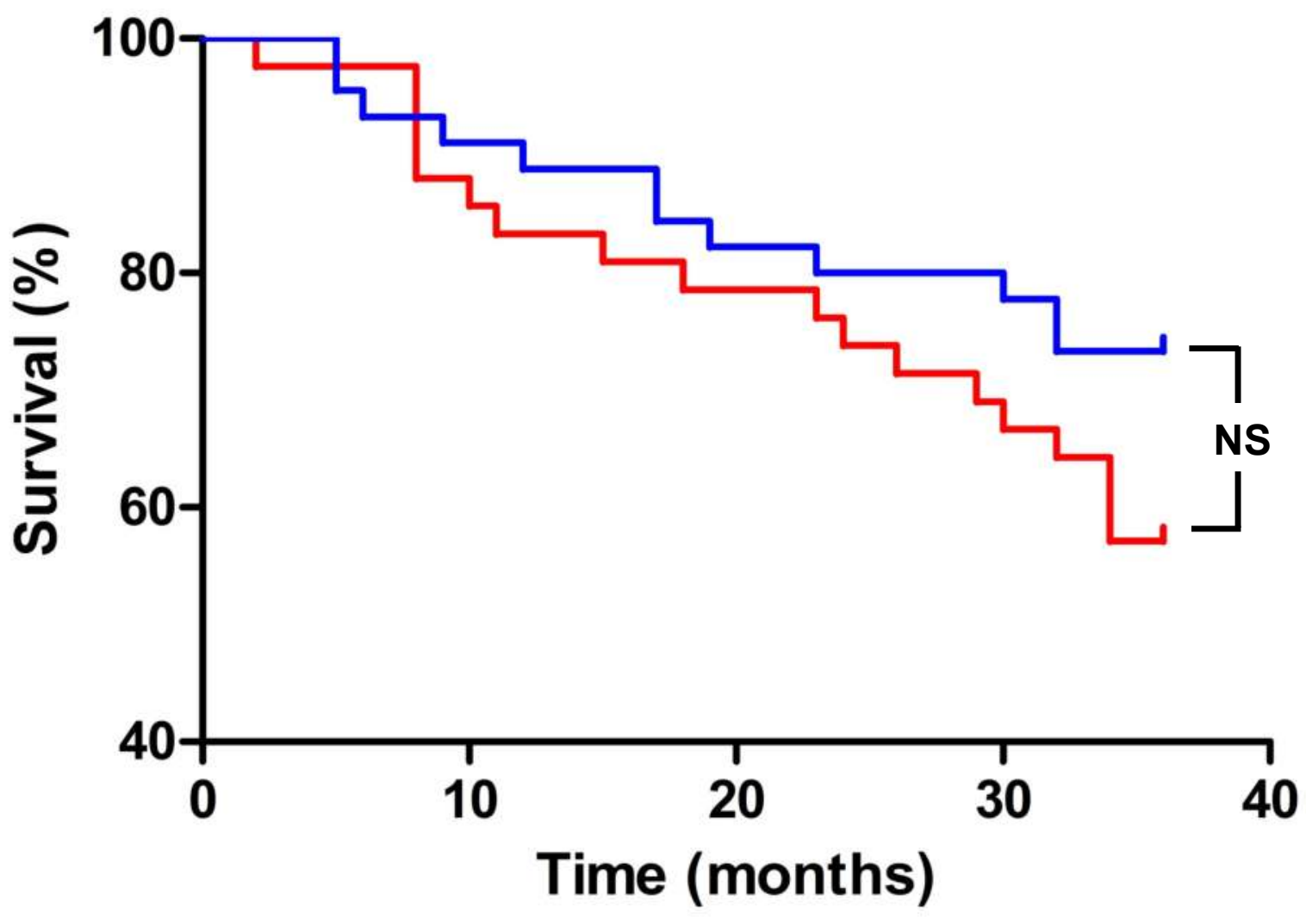

$\perp \mathrm{ACT} \perp$ Conservative therapy
- Our study showed significantly lower long-term amputation rate in patients treated by ACT in contrast to patients treated conservatively
- Our results suggest that ACT has the potential to be a promising treatment of diabetic patients with no-option CLI and DF 